\title{
This is not an instance of $(\mathrm{E})$
}

\author{
Teresa Marques
}

December 10, 2016

\begin{abstract}
Semantic paradoxes like the liar are notorious challenges to truth theories. A paradox can be phrased with minimal resources and minimal assumptions. It is not surprising, then, that the liar is also a challenge to minimalism about truth. Horwich (1990) deals swiftly with the paradox, after discriminating between other strategies for avoiding it without compromising minimalism. He dismisses the denial of classical logic, the denial that the concept of truth can coherently be applied to propositions, and the denial that the liar sentence expresses a proposition, but he endorses the denial that the liar is an acceptable instance of the equivalence schema (E). This paper has two main parts. It first shows that Horwich's preferred denial is also problematic. As Simmons (1999), Beall and Armour-Garb (2003), and Asay (2015) argued, the solution is ad hoc, faces a possible loss of expressibility, and is ultimately unstable. Finally, the paper explores a different combination of possibilities for minimalism: treating the truth-predicate as context-dependent, rejecting the notion that the liar expresses a proposition, and reinterpreting negation in some contexts as metalinguistic denial. The paper argues that these are preferable options, but signposts possible dangers ahead.
\end{abstract}

KEYWORDS: Truth; Minimalism; Liar paradox; Expressibility; Context-dependence; Propositions; Metalinguistic negation ${ }^{1}$

\section{Introduction}

Semantic paradoxes like the liar are notorious challenges to truth theories. A paradox can be phrased with minimal resources and minimal assumptions. It

\footnotetext{
${ }^{1}$ Acknowledgments I'm very grateful to Joe Ulatowski, Cory Wright, José Martínez, Jordi Valor, Manuel García-Carpintero, Peter Sullivan, and to two anonymous referees for this paper for discussion and objections raised. This work was supported by an FP7 Marie Curie Action, Grant Agreement Number: PIEF-GA-2012-622114; Grup de Recerca Consolidat en Filosofia del Dret, 2014 SGR 626, AGAUR de la Generalitat de Catalunya; project About Ourselves FFI2013-47948-P, Spanish Ministry for Economy.
} 
is not surprising, then, that the liar paradox is also prima facie a challenge to minimalism about truth. In his now classic book, Horwich (1990) offered a powerful demystifying defense of minimalism. The central claims of the theory are two: first, that truth has no hidden mysterious nature; second, that all there is to truth is the "trivial fact" that each proposition specifies its own condition for being true.

Minimalism is a variation of deflationism about truth, with some important differences from previous deflationary theories. ${ }^{2}$ An important background assumption, essential to minimalism, is that propositions are the primary bearers of truth-values. Propositions are the contents of mental states and speech acts, the things that are stated, believed, presupposed, etc. The truth of utterances, acts, or sentences, is to be derived from propositional truth. What propositions are, however, cannot depend on the notion of truth (Horwich, 1990, 17).

Minimalism about truth is not a theory about the nature of propositions, and Horwich avoids committing himself to a particular account of their nature. However, as this paper hopes to make clear, furthering the discussion on whether the liar expresses a proposition is an option available to Horwich, and can provide a different way to defuse semantic paradoxes.

One of the distinguishing features of Truth is the way it is organized as a set of answers to questions that raise "alleged difficulties" for minimalism. Among those is a question of whether the Liar poses a problem for deflationism. Horwich discriminates between four possible replies to the challenge. He dismisses (1) the denial of classical logic, (2) the denial that the concept of truth can coherently be applied to propositions, and (3) the denial that the liar expresses a proposition. But he endorses (4) the denial that the liar is an adequate instance of the truthschema.

Some of these answers are more popular than others. Horwich's choice, to restrict what counts as a correct instance of the truth-schema, faces various serious charges: namely ad hocery, loss of expressive power, and theoretical instability. Simmons (1999) and Beall and Armour-Garb (2003) argued that deflationists owe us an account of the grounds on which the truth-schema is restricted, but that, in its absence, the restriction is ad hoc and unjustified. In the absence of a justification, the restriction of the schema entails a significant loss of expressibility, and the inability to explain why certain prima facie paradoxical sentences are paradoxical. As an alternative, Beall and Armour-Garb

\footnotetext{
${ }^{2}$ Various forms of deflationist views about truth were defended by Ramsey (1927), Ayer (1935), Strawson (1950), Quine (1986), Field (1986, 1994), among others.
} 
(2003) suggest, deflationism should accept a revision of logic and embrace dialetheism. Simmons (1999) advocates a contextualist approach to 'true' that at first sight is not available to minimalists, since it is formulated for sentences as primary truth-bearers.

Recently, Horwich (2010) offered a different defense for the restriction of the schema, extending epistemicism, a theory about vagueness, to the semantic paradoxes. Epistemicism about the liar is the thesis that a liar proposition has a truth value, but that its truth-value is epistemically undetermined. However, epistemicism about the liar is ultimately an unstable view, as Asay (2015) persuasively argues, and puts too much pressure on minimalism. Asay (2015) very convincingly shows that Horwich (2010)'s extension of epistemicism about vagueness to the liar does not offer a stable response to the paradoxes. This paper takes the further step that Asay (2015) suggests, denying that liar sentences express propositions.

The paper is organized as follows. $\S 2$ offers a brief exposition of the minimalist theory of truth (MT), and of how Horwich proposes to block the inference

from a liar sentence to a contradiction. Sections $\S 3$ and $\S 4$ are the main parts of the paper. $\S 3$ offers a review of the arguments of Beall and Armour-Garb (2003), Simmons (1999), and Asay (2015) against Horwich's solution. §4 assesses the prospects of maintaining minimalism while rejecting that liar-like sentences express propositions. The proposal would require a combination of semantic contextualism and the recognition of a metalinguistic pragmatic mechanism of denial.

\section{Minimalism and the liar}

Minimalism about truth rests on the idea that each proposition specifies its own condition for being true. The minimal theory, MT, is a theory whose axioms are all and only the correct instances of the equivalence schema, (E). In (E), 'that $p$ ' or 'the proposition that $p$ ', is replaced by $\langle p\rangle$, resulting in

(E) $\langle p\rangle$ is true if and only if $p$.

In order not to restrict the theory to truths expressible by English sentences, or sentences in another language, a formulation of an expression referring to the structure of $(\mathrm{E})$ can be obtained by means of the same function, \langle\rangle .

$\left(\mathrm{E}^{*}\right)\langle\langle p\rangle$ is true if, and only if, $p\rangle$ 
This schema represents a function from propositions to propositions such that any application of the function to a proposition yields an axiom of the theory. Horwich repeats a slogan previously advocated by Quine - that the truthpredicate exists solely for the sake of our logical needs, namely to allow us to adopt an attitude towards a proposition even when we don't know what the proposition is ('what Oscar thinks'), or to cover infinitely many propositions ('everything Oscar said'). ${ }^{3}$ All further facts about truth are to be either explained or derived from (E). In particular, the theory can explain the logical role of the truth predicate in inferential reasoning.

Horwich endorses an equally minimal account of falsity, paired with a classical understanding of negation: ${ }^{4}$

(F) $(x)[x$ is false if, and only if, ( $x$ is a proposition and $x$ is not true) $]$.

This is equivalent to $\left(\mathrm{F}^{*}\right)$ or, more simply $\left(\mathrm{F}^{* *}\right)$ :

$\left(\mathrm{F}^{*}\right)\langle p\rangle$ is false if, and only if, not $\left[\langle p\rangle\right.$ is true]. ${ }^{5}$

$\left(\mathrm{F}^{* *}\right)\langle p\rangle$ is false if, and only if, not $p$. (Horwich, 1990, 76)

Here, 'not' is to be read as 'it is not the case that'. Negation is classically understood, the Law of Excluded Middle is held as valid, and double negation elimination is derivable. ${ }^{6}$

Consider now (1):

(1) is not true.

We can convene on using (1) to refer to the proposition expressed. Since, we are assuming, (1) expresses a proposition, it can instantiate (E). Let us refer to this instance of $(\mathrm{E})$ as ' $\left(\mathrm{E}_{(1)}\right)$ ':

But, from (1) and Leibniz's Law (substituting ' $\langle(1)$ is not true $\rangle$ ' with '(1)'), we have (3):

(3) $\quad\langle(1)$ is not true $\rangle$ is not true.

\footnotetext{
${ }^{3}$ (Horwich, 1990, 2-3)

${ }^{4}$ For a good discussion on whether classical negation is compatible with a use-theoretic account of meaning, see Kürbis (2015).

5 (Horwich, 1990, 72)

${ }^{6}$ (Horwich, 1990, 72)
} 
From (2) and (3), it follows that

(4) $\quad$ not $((1)$ is not true).

And with (3) and (4) we have a contradiction:

(1) is not true and not ((1) is not true).

The literature on the liar and deflationism about truth has taken different directions here. ${ }^{7}$ One tempting reaction is to deny that liar sentences like (1) are either true or false, i.e.

(6) Not $[\langle(1)$ is not true $\rangle$ is true or $\langle(1)$ is not true $\rangle$ is false].

This is equivalent to

(7) $\quad[$ Not $\langle(1)$ is not true $\rangle$ is true $]$ and Not $[\langle(1)$ is not true $\rangle$ is false].

But through the equivalence schemas for truth and for falsity, and double negation elimination, this leads to another contradiction: ${ }^{8}$

(1) is true and (1) is not true.

In Truth, Horwich's justification for the strategy adopted is striking in its simplicity:

But (1) [to deny classical logic] cuts too deep; (2) [to deny that the concept of truth can be coherently applied to propositions] also smacks of overkill; and (3) goes against the fact that, for any condition $C$, one might happen to believe that the proposition meeting that condition is not true - which (since any object of belief is a proposition) would imply that 'The proposition meeting condition $C$ is not true' expresses a proposition... Therefore the only acceptable solution is (4): only certain instances of the equivalence schema are correct. (Horwich, 1990, 41)

\footnotetext{
${ }^{7}$ See for example Field (2001, 2008).

${ }^{8}$ Soames (1999), for instance, took this as a motivation to argue that truth is a partially defined predicate. Another, perhaps less tempting, reaction, is to take the reasoning as showing what it seems to show: that indeed $\langle(1)$ is not true $\rangle$ is both true and not true as dialetheists assume. Several of the various options available are thoroughly explored in Field (2008). Many alternatives are not available to Horwich. On numerous occasions, he rejects the option of giving up classical logic or Bivalence because of non-referring terms (Horwich, 1990, 78), of vagueness (Horwich, 1990, 79), or of semantic paradoxes like the liar.
} 
Horwich (1990) claims that the principles that should guide the restriction of correct instances of schema (E) are first, that no liar-like contradictions follow; second, that the set of excluded instances is as small as possible; and finally, that there should be a constructive specification of the excluded instances that is as simple as possible (Horwich, 1990, 42).

Horwich refrains from endorsing a Tarskian approach to the liar - that of denying that a language can contain its own truth-predicate. ${ }^{9}$ On the Tarskian solution, there are object languages $L_{0}$, which lack any truth-theoretic notions. But at a meta-language $L_{1}$, there is a truth-predicate, 'true ${ }_{1}$ ' which can be applied to sentences of $L_{0}$, but $L_{1}$ does not contain its own truth-predicate. The truth-predicate for $L_{1}$ is 'true 2 ' and is contained in a further meta-language $L_{2}$, and so on. Horwich does not endorse the Tarskian solution, for a series of reasons that I won't go into here. One main reason is the fact that Horwich intends to account for a single use of 'true', which would correspond to our pre-theoretical intuitive notion.

In later writings, Horwich takes a page from Tarski's solution by restricting the application of 'true' to what he calls grounded propositions, where a proposition is grounded when it is entailed either by non-truth-theoretic facts or by those facts together with whichever truth-theoretic facts are entailed by them. ${ }^{10}$ Horwich explains that (1) is not a grounded proposition of $L_{1}$ because there are no facts of $L_{0}$, given (E), which entail either (1) or its negation.

This is an odd way for Horwich to explain ungroundedness, since on the assumption that propositions are independent from the languages that express them, it is odd to appeal to a hierarchy of languages to explain the ungroundedness of propositions. There is a tension between Horwich's resistance to resorting to a hierarchy of languages, and his later later willingness to do so (Horwich (2010)).

Horwich restricts the instantiation of schema (E), and holds the principle of Bivalence. This means that (9) is true:

(9) Either (1) is true or (1) is false.

There is no objection to assuming that (1) is true (or that it is false). But it is not possible to come to know which it is, because (1) is ungrounded - there are no non-truth-theoretic facts that entail it (or its negation). We can't know

\footnotetext{
${ }^{9}$ As in, for instance, Tarski (1936), Kripke (1975).

${ }^{10}$ (Horwich, 2005, 81-82), (Horwich, 2010, 91).
} 
whether (1) is true or not. Finally, $\left(\mathrm{E}_{(1)}\right)$ is an unacceptable instance of (E).

Horwich's view is a form of semantic epistemicism (Beall and Armour-Garb, 2005, 85). Epistemicism about vague predicates was defended by Sorensen (1988) and Williamson (1994). According to epistemicism about vagueness, it is indeterminate whether the vague predicate 'tall' applies to a borderline tall Sally, although determinately either 'tall' applies or it does not. Likewise, it is epistemically indeterminate, according to Horwich, whether (1) is true or not.

Beall and Armour-Garb (2005) allege that semantic epistemicism gives a principled motivation for the restriction of schema (E). Horwich is committed to Bivalence, which justifies his commitment to (8). More importantly, Beall and Armour-Garb claim that Horwich's commitment to (9) is also justified:

(10) It is conceptually impossible to know that (1) is true and it is conceptually impossible to know that (1) is false.

In general, it is impossible to know $\langle\langle A\rangle$ is not true $\rangle$ for any proposition $\langle A\rangle$ wherever $\langle\langle A\rangle$ is not true $\rangle$ cannot be inferred through the truth-schema $(\mathrm{E})$, as is the case with (1).

According to Horwich, a proposition is epistemically determinate just in case it is conceptually possible to come to know its truth-value. Conversely, a proposition is indeterminate just in case it is not conceptually possible to know its truth-value, and this impossibility is semantically induced. ${ }^{11}$ Indeterminacy arises in different ways for sentences with vague predicates and for liar sentences. In the former case, the 'vagueness-induced-indeterminacy' results from the fact that use-regularities do not decide between the inclination to apply the predicate and the inclination not to apply it. In the latter case, use-regularities to apply the truth predicate generate conflicting inclinations (Beall and Armour-Garb, 2005, 91-92).

The next section will review these authors' earlier arguments against MT, and the persuasive case made by Asay (2015) against the plausibility of the epistemicist solution for the liar.

\footnotetext{
${ }^{11}$ Not all conceptual impossibilities are "semantically induced". "Semantically induced" means that they arise, as in the present cases, from semantic notions or concepts, or are caused specifically by semantic indeterminacy or underdetermination.
} 


\section{Objections to the restriction of schema (E)}

There are objections to Horwich's restriction of schema (E) that present serious problems for minimalism. Simmons (1999) and Beall and Armour-Garb (2003), among others, argued that the restriction is ad hoc. Although they focus on disquotationalist versions of deflationism, similar problems arise for minimalism. The epistemicist solution is ultimately an unstable position, as Asay (2015) argues. This section offers a review of some of the objections. In the last section of the paper, I'll suggest that denying that the liar expresses a proposition is a more acceptable solution than just saying that only certain instances of the equivalence schema are correct.

\subsection{Ad hocery and loss of expressibility}

A problem for minimalism is that it seems that there is no principled way for a deflationist to restrict the instantiation of the equivalence schema by paradoxical sentences. Beall and Armour-Garb (2003) insist that the dilemma for the deflationist is to either make an ad hoc restriction of the schema, or accept inconsistency. This is an important step in their argument that deflationists should be dialetheists. I reconstruct part of their argument below.

A core thesis of deflationary truth-theories is the claim that the value of truth resides in the function it plays. The utility and expressive role of truth is manifest in the way it allows us to generalize over an indefinitely large number of propositions, both to express infinite conjunctions and to commit to truths that would otherwise be inaccessible (Horwich, 1990, 2-3). It is essential to truth's logical function that the status of a truth generalization is explained by reference to the status of the infinite conjunction. For example, (11) entails an infinite conjunction of sentences of the form in (12).

(11) Everything that Tarski said on 27 March 1934 is true.

(12) If Tarski said ' $p$ ' on 27 March 1934, then $p$.

Now, if (11) is true, false or paradoxical, it must be because the infinite conjunction of sentences it entails is itself true, false or paradoxical (Beall and ArmourGarb, 2003, 314). But suppose all Tarski said on that day was (1). Given that (1) is paradoxical, it cannot adequately instantiate the truth-schema (E). If Tarski said (1), we cannot infer (13) from (11): 
If Tarski said that (1) is not true on 27 March 1934, then (1) is not true.

This is where the problem for deflationism arises. We should be able to ask about the truth status of (11) itself. The deflationist would presumably want to say that (11) is also paradoxical - the truth-status of a truth generalization is to be explained by reference to that of the infinite conjunction it expresses. But if the only thing Tarski uttered was (1), there is nothing else on which to base the paradoxicality of (11).

Horwich could say that the paradoxicality of (11) is due to the fact that it is not an adequate instance of the truth-schema. ${ }^{12}$ This sounds problematic: we want to explain why something is not an adequate instance of (E), and then use the notion of an adequate instance to explain paradoxicality. But we only discover that (11) is paradoxical if it instantiates the schema in the first place. Horwich's possible rejoinder, that the paradoxicality is due to (11) being an inadequate instance of the schema, sounds viciously circular. The sentence is paradoxical because it is not a appropriate instance of the schema, and it is not an appropriate instance because it leads to paradox.

If we restrict the truth-schema to non-paradoxical instances, then we cannot use it to explain the paradoxicality of (11) in terms of the paradoxicality of (13). Since we cannot disquote, and the only thing Tarski said was '(1) is not true', the conjunct entailed by (11) will be (14):

If Tarski said '(1) is not true' on 27 March 1934, then '(1) is not true' is true.

It follows that the truth status of the conjunct depends on the status of

'(1) is not true' is true.

Beall and Armour-Garb (2003)'s point can be colloquially rephrased with reference to propositions through a that-clause to indicate the content of Tarski's speech act in (16):

(16) If Tarski said that (1) is not true on 27 March 1934, then it is true that (1) is not true.

(17) $\quad\langle(1)$ is not true $\rangle$ is true.

\footnotetext{
${ }^{12} \mathrm{I}$ 'm grateful to an anonymous reviewer for pointing out the need to elaborate on the reply.
} 
Now, the proposition expressed by (1) is not a proper instance of the truthschema (E). It follows that the paradoxicality (11), (14), and (16) cannot be explained. 'True' is ineliminable from (15) and from (17), because we cannot disquote or denominalize. Therefore, minimalism entails a loss in expressibility and explanatory power (Beall and Armour-Garb, 2003, 315).

It entails a loss in expressibility because it admits that there are propositions that may be true, but that cannot instantiate the truth-schema. It entails a loss in explanatory power because minimalism purports to capture all facts about truth through instances of the truth-schema, but it admits the existence of (possibly) true propositions that are not legitimate instances of (E), and hence of truths that the theory does not capture. This appears to be a counterexample to the central claim of minimalism - that minimalism captures all facts about truth. ${ }^{13}$

Simmons (1999) argument is slightly different (there is no need, for present purposes, to reconstruct the entirety of his argument). He starts by making a similar point about the restriction of the truth-schema, offering an assessment of the deflationist's option to classify paradoxical sentences as ungrounded (Simmons, 1999, 465-467). He admits that a well-justified account of ungroundedness could motivate the restriction of the truth-schema to grounded sentences. Like Beall and Armour-Garb (2003), he shows that the restriction entails giving up the idea that the truth predicate can be eliminated from every ordinary utterance in English. Ungrounded sentences are beyond deflationist definitions.

The pressing problem for deflationism comes from strengthened liar sentences (Simmons, 1999, 471). The deflationist owes us an account of 'not true'. On Horwich's definition,

(F) $(x)[x$ is is false if, and only if, ( $x$ is a proposition and $x$ is not true) $]$.

$\left(\mathrm{F}^{*}\right)\langle p\rangle$ is false if, and only if, not $\left[\langle p\rangle\right.$ is true]. ${ }^{14}$

$\left(\mathrm{F}^{* *}\right)\langle p\rangle$ is false if, and only if, not $p$.

A consequence of the definition is that 'not true proposition' is indistinguishable from 'false proposition'. (F) presumably ranges over all propositions and states conditions for their falsity. $(\mathrm{F})$ is equivalent to $\left(\mathrm{F}^{*}\right)$ because on MT the condition that $x$ is a proposition is redundant. Falsity and untruth are equivalent. Since we can't instantiate schema (E) with (1), presumably we can't correctly

\footnotetext{
${ }^{13}$ Thanks to another anonymous reviewer for insisting on the clarification of this point.

${ }^{14}$ (Horwich, 1990, 72)
} 
instantiate $(\mathrm{F})$ or $\left(\mathrm{F}^{*}\right)$ either. The equivalence between $\left(\mathrm{F}^{*}\right)$ and $\left(\mathrm{F}^{* *}\right)$ does not hold for a paradoxical sentence like (1), since we can't use $\left(\mathrm{E}_{(1)}\right)$ to derive $\left(\mathrm{F}^{* *}\right)$.

If '(1) is not true' is ungrounded, perhaps we should distinguish 'not true' from 'false'. That is, should we be able to truly say that (1) is not true, without having to say that it is false? 'Not true' could then apply to anything that is either not a proposition or is false.

NotT $(x)[x$ is not true if, and only if, ( $x$ is not a proposition or $x$ is false)].

But Horwich rejects the idea that paradoxical sentences fail to express propositions. Could he capture another sense in which 'not true' and 'false' are not equivalent? On one reading, 'not true' is equivalent to 'false'. We can call this the weak reading. On a strong reading, 'not true' is clearly distinguished from 'false':

NotT $^{*}\langle p\rangle$ is not true if, and only if, [ $\langle p\rangle$ is false or $\langle p\rangle$ is ungrounded].

Horwich didn't want to reject Bivalence. Since, he claims, paradoxical sentences express propositions, he can't consistently say that an ungrounded proposition is one that is not true, since an ungrounded proposition is, in any case, either true or false. To allow a different sense of 'not true' is to allow a proposition to fail to be true in more ways than one, and thereby to reject Bivalence.

Simmons (1999) points to a contextualist alternative, by drawing attention to different things we may want to say about the liar. He argues that strengthened reasoning should motivate us to adopt a contextualism approach to truth. Take (L), and suppose that Aristotle writes (L) on the blackboard, believing that Plato is teaching in room 101.

(L) The sentence written on the board in room 101 is not true.

(L) is a liar sentence, because Aristotle is in room 101, not Plato. (L) is paradoxical - it is the sentence written on the board of room 101. The familiar liar reasoning would land us in a contradiction: "So (L) isn't true. That is, we may infer $(\mathrm{P})$. The sentence written on the board in room 101 is not true" (Simmons, 1999, 470). Given (P) ("(L) isn't true") and what (L) says, it follows that

(R) (L) is true.

This is a reasoning that appears correct, but which, for the reasons we pointed out above, is not expressible in MT. On Simmons proposal, in contrast, 
Contextual accounts provide for reflective evaluations of pathological sentences. (L) is true in the context of $(\mathrm{R})-(\mathrm{L})$ is gappy only relative to its context of utterance, and in a suitably reflective context, $(\mathrm{L})$ may be evaluated as true. The Truth-Teller $(\mathrm{J})$ will be reflectively evaluated as false, since it is pathological, and so not true, yet it says it is true. A Liar sentence like (1) ('(1) is false') will also be false, because it is pathological, and so not false, yet it says it is false. The contextual analysis takes into account the pathology of the ungrounded sentences, and accommodates the evaluation of them according to their pathology and what they say. Now recall the disquotational strategy of the previous section: we exclude Liarlike sentences from the disquotational definition of truth in a principled way (via the notion of ungroundedness). To the charge that 'true' is not eliminable from ungrounded sentences, the disquotationalist's reply was: "But they are pathological anyway; it's acceptable to set them aside." However, according to the present contextual account, these ungrounded sentences are true or false. Ungrounded sentences are truths and falsehoods from which 'true' and 'false' cannot be eliminated. And if there are truths (and falsehoods) expressed by ineliminable uses of 'true' and 'false', then so much the worse for the disquotational theory. (Simmons, 1999, 471)

To be fair, what Simmons shows is that 'true $L$ ' is ineliminable, not that 'true' is. If truth is context-sensitive, there are no unsubscripted uses of a truthpredicate. Is Simmons right that the ineliminable uses of 'true' and 'false' allow for the expression of truths and falsehoods? Is the ineliminability of 'true' and 'false' a problem for minimalism?

In summary, minimalism loses expressibility, because there are truth-valued propositions whose truth-conditions cannot be stated through instances of the truth-schema. Their apparent paradoxicality (if it is such) is not explained by the theory, due to the restriction of the truth-schema. Since the truth-schema is restricted, there are uses of 'true' that don't perform the logical function that minimalism declares is its only role.There are propositions that are true (or false), and whose truth (or falsity) is not captured in "the trivial fact that they specify their own condition for being true". There are truths and falsehoods that are expressed by ineliminable uses of 'true' and 'false'. This puts considerable pressure on the theory. Without a further reason for the restriction of the truth-schema, it is not just ad hoc, but also self-defeating.

In $\S 4$, I'll argue that a contextualist about the truth-predicate can be a deflationist, without accepting that there are ungrounded sentences that have truth-values. 


\subsection{Instability}

Does the epistemicist justification of the restriction of schema (E) provide the much-needed rationale? Beall and Armour-Garb (2005) believe it does, but I think they are mistaken, and Asay (2015) makes a convincing case describing the reasons why. Epistemicism about the liar means that:

(i) Either (1) is true or (1) is false (example (8) above).

(ii) It is not possible to know that (1) is true and it is not possible to know that (1) is false (example (9) above).

(iii) $\left(\mathrm{E}_{(1)}\right)$ is not an acceptable instance of $(\mathrm{E})$.

Let us start with (iii). We can make normal inferences involving truth with vague indeterminate sentences. If true, (17) and (18) entail the truth of (19):

(18) $\langle$ Sally is tall $\rangle$ is true if, and only if, Sally is tall.

(19) Sally is tall.

(20) $\quad\langle$ Sally is tall $\rangle$ is true.

Even if (19) and (20) are unknowable, we know that (18) is unproblematically true. (19) is contingent - if Sally had spent several months in the space station, she would have been taller. Even though we cannot know if she is tall or not, the biconditional in (18) is true. Epistemic indetermination, in the case of vagueness, does not motivate a restriction of the truth-schema.

Now, since $\left(\mathrm{E}_{(1)}\right)$ is not an acceptable instance of $(\mathrm{E})$, we cannot know it to be true.

$\left(\mathrm{E}_{(1)}\right)\langle(1)$ is not true $\rangle$ is true if, and only if, (1) is not true.

Asay (2015) objects to the characterization of $\left(\mathrm{E}_{(1)}\right)$ as merely unacceptable or incorrect. Sentence (1) expresses a proposition and has a truth-value (given (i)). Hence, the two sides of $\left(\mathrm{E}_{(1)}\right)$ are themselves propositions that are either true or false (Asay, 2015, 682). Given Bivalence, $\left(\mathrm{E}_{(1)}\right)$ must also be either true or false. The reason why we can't know that it is true is not because $\left(\mathrm{E}_{(1)}\right)$ is incorrect. We can't know it to be true, because if it were true, it would be equivalent to a contradiction. Hence, we know it is not true. Given Bivalence, it must be false.

Asay shows that $\left(\mathrm{E}_{(1)}\right)$ has further interesting logical properties. In $\left(\mathrm{E}_{(1)}\right)$, 'is true' plays a consistent and stable logical role: namely it behaves as 'is false' does for regular non-liar instances of $\left(\mathrm{F}^{*}\right)$. 'Is true' is not denominalizable for 
liar propositions and their truth-theoretic iterations, but it is "doubly denominalizable". As Asay says, although we can't denominalize or renominalize 'is true' from one step to the one immediately after, we can do so to two steps away (the steps indicated in boldface) (Asay, 2015, 683):

\section{$\langle(1)$ is not true $\rangle$}

$\langle\langle(1)$ is not true $\rangle$ is true $\rangle$

$\langle\langle\langle(1)$ is not true $\rangle$ is true $\rangle$ is true $\rangle$

$\langle\langle\langle\langle(1)$ is not true $\rangle$ is true $\rangle$ is true $\rangle$ is true $\rangle$

Moreover, we can denominalize and renominalize with 'is false' or (equivalently, in MT) 'is not true' (Asay, 2015, 684):

\section{$\langle(1)$ is not true $\rangle$}

$\langle\langle(1)$ is not true $\rangle$ is not true $\rangle$

$\langle\langle\langle(1)$ is not true $\rangle$ is not true $\rangle$ is not true $\rangle$

$\langle\langle\langle\langle(1)$ is not true $\rangle$ is not true $\rangle$ is not true $\rangle$ is not true $\rangle$

These logical features are a damning indictment of minimalism. They show that 'is not true' (and 'is false') are devices that enable denominalization and renominalization. As a result, the class of propositions whose T-biconditionals are false are those whose "F-biconditionals", like the following, are true:

$\langle p\rangle$ is not true [is false] if, and only if, $p$.

"So every time Horwich strikes a T-biconditional from the minimalist theory, he should replace it with its corresponding F-biconditional." (Asay, 2015, 690-691)

Why is this a problem? On Horwich's theory "the acceptance property governing our total use of the word 'true' is the inclination to accept instances of the schema 'the proposition that $p$ is true if and only if $p$ '" (Horwich, 1990, 45). Now, Horwich also claims that two words mean the same when they express the same basic acceptance property. This means that 'not true' ('false') in the schema above means the same as 'true' does in correct instances of (E). For a certain set of propositions, there is a property designated by 'not true' such that this property behaves as 'true' does for regular propositions - i.e., as a device that allows denominalization and renominalization. It follows that 'not true' in $\langle(1)$ is not true $\rangle$ expresses the same property as in $\langle\langle$ Sally is tall $\rangle$ is true $\rangle$. 
Either a minimalist account is correct, and all our uses of 'true' are governed by this "acceptance property", or our use of the word 'true' is not entirely explained by our disposition to accept instances of the truth-schema, and minimalism is not correct.

On the one hand, if minimalism is correct, then the occurrences of 'true' and 'not true' above are entirely defined by their role as devices for denominalization and renominalization. If 'not true' for liar propositions means the same as 'true' for regular propositions, then 'not true' in the liar ascribes truth to itself. Since, by stipulation, the liar ascribes non-truth to itself, we have a contradiction. But Horwich stated as a condition on the acceptability of an account of the liar that it avoids liar-like contradictions. To avoid the contradiction, the minimalist could collapse the distinction between truth and untruth (or, to the same effect, truth and falsity), but this would make the theory trivial.

On the other hand, if the use of 'not true' in (1) is not governed by our disposition to accept instances of (E) (and the relevant use regularities that govern 'not'), then minimalism is false: there is more to truth and non-truth than the denominalization and renominalization function (Asay, 2015, 693). §3.1 reached a similar conclusion: that there seems to be more to the truth-predicate than can be captured in the (E) schema. The assumption that liar sentences express propositions, which must be either true or false, entails that there are truths and falsehoods whose truth-status is not explained by the denominalization function that is captured in the truth-schema. Minimalism is hence an unstable view.

Asay also raises other problems for epistemicism. One concerns the epistemicist justification to restrict the truth-schema. Claim (ii) (see above) expresses the idea of epistemic indeterminacy. Yet, as Asay points out, Horwich is relying on disconnected sources of (alleged) indeterminacy. Vague examples like (19) are indeterminate because use-regularities for 'tall' do not suffice for us to know whether Sally is tall or not, even though she either is or isn't (assuming epistemicism). Use regularities are silent in this case.

The epistemicist explanation for why the liar is indeterminate is notably different. The liar is indeterminate not because use-regularities do not suffice for us to know, either way, whether (1) is true or not true, but because assuming it to be one or the other leads to conflict. Use-regularities in this case are, not silent but conflicting. There is no foreseeable reason why conflict should specifically entail epistemic indeterminacy.

The explanation of why (1) is ungrounded has further strange consequences for the minimalist. Recall that ungroundedness is not tantamount to lack of 
truth-value, nor to the failure to express a proposition. The liar is ungrounded because there are no non-truth-theoretic facts that entail it (or its negation), and assuming that it is true or false leads to contradiction. Yet, the absence of non-truth-theoretic facts that entail it or its negation is a feature that (1) shares with the truth-teller, (21):

(21) is true.

This means that (21) should also be ungrounded and paradoxical. If the rationale to restrict (E) from being instantiated with (1) is its ungroundedness, then the same rationale holds with (21), even though no contradiction arises from doing so.

$\left(\mathrm{E}_{(21)}\right)\langle(21)$ is true $\rangle$ is true if, and only if, (21) is true.

$\left(\mathrm{E}_{(21)}\right)$ and (21) should entail (22).

(21) is true if, and only if, (21) is true.

This is a tautology, and apparently provably true. But it cannot be derived, because (21) is ungrounded and as such should not instantiate (E) (Asay, 2015, $686)$.

Therefore, we can't give the same account of the indeterminacy of (21) and (1). The use-regularities for truth do not give rise to any conflict in the case of (21). If it's true, it's true; if it's false, it's false. Of course, tautologies are meaningful. Consequently, the explanation of the indeterminacy of (21) cannot be exactly the same as that of (1), even though they are both self-referential truththeoretical propositions. It is unclear, hence, why (21) should be indeterminate, and prevented from instantiating (E). Therefore, the restriction imposed on (21) is ad hoc.

Asay (2015) convincingly argues that Horwich's justification for the epistemic indeterminacy of the liar is unprincipled. The idea that the liar is epistemically indeterminate because the regularities of use of 'true', 'false', and 'not' give rise to conflicts applies only to the liar and the strengthened liar. The same explanation cannot be extended to the truth-teller, which presumably should deserve a similar kind of account given their similar self-referential and truththeoretical nature (Asay, 2015, 678); nor can it apply to the vagueness case. There are thus three different kinds of indeterminacy, which arise from distinct phenomena, and deserve different explanations. To say that they are all cases of 
epistemic indeterminacy does not amount to giving a principled unified account.

A final and crucial criticism concerns the explanation of ungroundedness. Asay asks the epistemicist to explain why (i) is right, i.e., why it is that either (1) is true or false. If (1) is one or the other, given Bivalence, what makes it so? Contrast with 'Sally is tall'. Even if we can't know whether Sally is tall or not, (18) is either true or false. Furthermore, (18) is contingent on Sally's height, and could have been knowably true (or knowably false).

Is (1) contingently true? What would it take for (1) to be determinately true (or false) meaning what it does? Since it does not depend on any nontruth-theoretic facts, there is no "contingently existing thing in the universe" responsible for its truth, and nothing in the world could have made a difference for its truth-value (Asay, 2015, 695). Moreover, there is nothing that the minimalist can tell us about the regularities of our use of 'true' or 'false' that could settle the matter either way. There are also, thus, no truth-theoretical facts (short of changing words' meanings) that could settle (1)'s truth or untruth. Hence, there is no contingent truthmaker for (1)'s truth (or falsity).

Asay further claims that there is also no necessary truthmaker either. Which necessary existent could serve as a truthmaker for the liar? It could be that (1) is its own truthmaker - but this is not better than saying that nothing is. Even if it is accepted that not all truths have a truthmaker, it must be that what is true supervenes on what exists and its properties. There must be some difference in what exists in the world, or its properties, if (1) is to be true instead of false, or false instead of true. If epistemicists claim instead that (1) is a brute truth, they fail anyway to answer a question that only arises for them: why is (1) true and not false?

In summary, claiming that (1) has a truth-value that is necessarily unknown has no explanatory virtues, yet raises new problems that other accounts do not face (Asay, 2015, 697). Epistemicism does not provide a principled defense of the restriction of schema (E). It is an ad hoc and unstable solution. Asay hints that it would be preferable for Horwich to deny the meaningfulness of the liar. The final section will try to show that this is a preferable solution.

\section{There is no liar proposition?}

Horwich dismissed three alternatives for dealing with the liar. They were: (1) to deny classical logic, (2) to deny that the concept of truth can be coherently 
applied to propositions, and (3) to deny that there is a proposition expressed by the liar sentence. Instead, Horwich argued for (4) only certain instances of the equivalence schema are correct, but that liar (and related) sentences express propositions and which are truth-valued.

$\S 3$ showed that the epistemicist justification for (4) is ad hoc, loses expressibility and explanatory power, and ultimately makes minimalism about truth unstable. It raises a stack of problems which make it clear that (4), by itself, is not an acceptable solution, let alone the only one. It has no explanatory virtues, but raises problems that other views do not face. Assuming that Horwich wants to preserve Bivalence and classical logic, the next alternative would be to opt for (3), to deny that there is a proposition expressed by the liar sentence.

\subsection{The motivation to deny that there is a proposition}

There are two reasons why Horwich claims that the liar expresses a proposition:

(i) Propositions are the contents of beliefs.

(ii) For any condition $C$, someone may believe that the proposition meeting that condition is not true.

However, offering (i) and (ii) as reasons for thinking that a sentence like (1) expresses a proposition is question-begging. For anyone to believe that that proposition meets condition $C$ and is not true, there must first be a proposition that meets condition $C$ in the first place. If there is no proposition expressed by (1), then no one can believe of it that it meets condition $C$. In general, a sincere utterance of the sentence 'The proposition meeting condition $C$ is not true' does not necessarily denote any proposition.

This is not a novel proposal. Strawson (1950) gave the following example. Suppose one utters (23) out of the blue, and does not demonstrate anything (red or otherwise) in her environment.

This is a fine red one.

A use of 'this' requires that something be demonstrated in context for any true or false proposition to be expressed about whatever the context offers as the referent. Otherwise, there is no proposition. This has consequences for sentences like (25) and (26).

(24) It's not true that this is a fine red one. 
Mary believes that this is a fine red one.

(25) doesn't ascribe a belief to Mary, because the that-clause does not designate a proposition. (24) does not express a proposition either. In other words, (26)(28) do not designate propositions, and (28) in particular is not an instance of $\left(\mathrm{E}^{*}\right)$ :

(26) 〈This is a fine red one〉

(27) 〈रThis is a fine red one $\rangle$ is true $\rangle$

(28) $\quad\langle\langle$ This is a fine red one $\rangle$ is true if, and only if this is a fine red one $\rangle$

Sentences that are not truth-apt shouldn't be a problem for a theory of truth. Moreover, Horwich (1998) does not deny that context-sensitivity exists (Horwich, 1998, 83). Horwich further admits that even predicates may be contextsensitive, if the propositional constituents they express are fixed by a combination of their meaning and the context where they appear (Horwich, 1998, 109n). In different contexts a given predicate $P$ may express different contents, and if the context doesn't make the required contribution, no content is expressed.

(23) expresses no proposition, and sentences with embedded occurrences of it express no proposition either. It is compatible with Horwich's views about how meaning determines propositional constituents that meaningful sentences may fail to express propositions, and that belief-like states may fail to relate their bearers to any propositions.

In the previous section, I said that Asay (2015) hinted at the possibility of declaring that the liar expresses no proposition. If the liar expresses no proposition, this is a good reason for restricting instantiation of (E). It is a better motivation to say liar-like sentences cannot be correct instances of (E) than it is to say that liar-sentences express truth-valued propositions, which nonetheless can't acceptably instantiate (E).

There are two options available to Horwich here. First, he could say that 'true' is itself a context-sensitive predicate. Second, he could say that whether 'true' ascribes a property to anything at all depends on context. In certain unsuccessful situations, there might be no suitably designated proposition to which truth or falsity could be ascribed. I think that the two options are compatible, depending on how they're developed.

On the first option, context-dependence means that 'true' expresses different properties on different occasions of use, depending on the contribution made by 
the context. This is how Simmons (§3.2.) contextualist proposal works. Horwich may want to resist the context-sensitive solution for 'true' because admitting that 'true' is context-sensitive can be seen as accepting that 'true' does not express one single property. Moreover, Simmons's proposal takes sentences in contexts as truth-bearers, not propositions. As a result, a contextualist account of the truth-predicate like Simmons's is not straightforwardly applicable to minimalism, which takes propositions as truth-bearers. But I think that minimalism can accept a form of context-sensitivity about the truth-predicate that does not commit minimalism to a problematic multiplicity of truth-properties.

Kennedy and McNally (2005) offer a contextualist semantics for gradable adjectives. On a version of their view, 'tall' denotes a measure function - a function from objects to degrees on a scale (in this case, of height), which itself is an ordering of degrees. This allows a natural account of the truth conditions of comparative claims like 'Sally is taller than Jenny.' 'More' (or the corresponding suffix) is interpreted so that the sentence is true just in case the degree that the interpretation of the adjective ascribes to the interpretation of 'Sally' exceeds the degree that it ascribes to the interpretation of the phrase headed by 'than'. Similarly natural truth-conditions are given for sentences such as 'Max is 2 meters tall' and 'Kathrin is very tall.'

To deal with the positive form of the adjective, the account posits an absolute morpheme in the syntax of a sentence such as

[Speaker, assuming that Kathrin is $1.85 \mathrm{~m}$ tall, and discussing the height of women in philosophy, says:] Kathrin is tall.

The sentence in (29) combines with the measure function denoted by 'tall' to yield a function from individuals to truth-values. The function takes an individual $x$ to True just in case the degree of height of that individual is at least as great as the average degree for the reference class, either contextually given or made explicit by the 'for a philosopher'.

Why is this of interest here? One could be concerned that a contextualist semantics for gradable adjectives entails that different utterances of sentences of the form ' $x$ is tall' express different properties. In a sense, that is true. The comparison class, the degree of precision, or 'ways to draw the line' between tall people and the rest will vary, depending on the contexts of use. Yet, in a fundamental sense those properties are related: they are all measure functions for degrees of height of individuals. Similarly, one might be concerned that treating 
the predicate 'true' as context-dependent could entail that 'true' does not denote a single property, but distinct, albeit closely related, properties. This is not as as problematic as it may appear. Just like 'tall' denotes, in different contexts, distinct but closely related measure functions for height, so can 'true' denote, in different contexts, distinct but closely related denominalization functions for propositions.

The second option for Horwich is to say that whether or not 'true' ascribes a property to anything at all depends on context. Horwich restricts the instantiation of the truth-schema to grounded propositions, where a proposition is grounded when it is entailed either by non-truth-theoretic facts or by those facts together with whichever truth-theoretic facts are entailed by them. ${ }^{15} \mathrm{He}$ says that (1) is not a grounded proposition because there are no non-truththeoretic facts that entail either it or its negation. We saw at the end of the last section that this is a deeply unstable (if not untenable) position to hold.

But Horwich could say instead that only sentences that express propositions can instantiate (E). He could then say that if a sentence contains an ineliminable occurrence of 'true', then it doesn't state anything that could make a "difference in the world regarding what exists", i.e., it doesn't state anything at all (Asay, 2015, 696). Sentences like (1) don't make any difference in the world, because they don't say anything that is either entailed by "non-truth-theoretic facts or by those facts together with whichever truth-theoretic facts are entailed by them". This can be claimed to be a symptom of the fact that liar sentences express no proposition.

To deny that liar sentences express propositions is not a novel proposal for a deflationist; nor am I the first person to make the suggestion. Beall (2001) argued that the ineliminability of 'true' from liar sentences is an independent reason for deflationists to argue that the paradoxical sentences of the liar family don't express propositions. In that paper, Beall argues that the spirit of deflationism offers an independent reason to say that sentences like the simple liar, the strengthened liar, and the truth-teller 'say nothing'. This is a non-ad hoc explanation that is available to deflationism, but less obviously so to other theories. As he says,

The nice thing about this reply is that it is independent of the paradoxes in question. (Beall, 2001, 128)

\footnotetext{
${ }^{15}$ (Horwich, 2005, 81-82), (Horwich, 2010, 91).
} 
Asay's point that I quoted above, that these paradoxical sentences don't make a "difference in the world regarding what exists" is a consequence of the ineliminability of the truth-predicate.

I hinted earlier that a minimalist's denial that paradoxical sentences express propositions is consistent with a context-dependent account of the truthpredicate. Recall how contexts are understood. By 'context' we usually mean the concrete situation in which a sentence is used. There are different theories about what contexts are and how they contribute to what is said by a use of a sentence. On Kaplan (1989)'s conception, a context is a formal set of parameters (including speaker, time, place, a possible world, etc.) which contributes to determine what is said (which proposition is expressed) by a use of a sentence. On Stalnaker (1978, 2002, 2014)'s view, a context is a body of information that is available, or presumed to be available, as a resource for communication - a context set. A context set is a set of possible worlds compatible with the common knowledge of the interlocutors. On Lewis (1980)'s view, these two accounts are combined:

Whenever a sentence is said, it is said at some particular time, place, and world. The production of a token is located, both in physical space-time and in logical space. I call such a location a context. That is not to say that the only features of context are time, place, and world. There are countless other features, but they do not vary independently. They are given by the intrinsic and relational character of the time, place, and world in question. The speaker of the context is the one who is speaking at that time, at that place, at that world... The audience, the standard of precision, the salience relations, the presuppositions. . of the context are given less directly. They are determined, so far as they are determined at all, by such things as the previous course of the conversation that is still going on at the context, the states of mind of the participants, and the conspicuous aspects of their surroundings.(Lewis, 1998, 28-29 of the reprint) (My emphasis.)

Contexts may fail to determine, for instance, the relevant salience relations or the standards of precision. Consider a use of the predicate like 'tall' in a conversational context where either the salience relations for the relevant comparison class, or the standard of precision, are indeterminate, or there isn't one single relevant comparison class or standard of precision for 'tall' shared by speaker and audience (e.g., one is thinking of the comparison class of women in basketball, the other of the comparison class of women in philosophy). There is 
no such thing as the relevant comparison class or standard of precision that is compatible with the interlocutors' common knowledge. That means that in the context there is no single measure function for height denoted by 'tall'. Contextualism about gradable adjectives is thus compatible with the view that in certain contexts no proposition is expressed.

Mutatis mutandis, contextualism about 'true', combined with minimalism, is compatible with the view that in certain contexts no proposition is expressed. Minimalism about truth is a view about the kind of property that is expressed by 'true'. According to minimalism, truth is a denominalizing function. If minimalism admits that 'true' is context-dependent, it commits to the expression of different related denominalizing functions. These denominalizing truthproperties are expressible in contexts where tokens of the predicate 'true' can work as disquotational devices. If the predicate is ineliminable, then no denominalizing function for propositions is denoted. This is at least a coherent view to hold.

A similar view was defended by Goldstein $(2000,2001)$, who argued that no statement is made by the liar and the truth-teller sentences. He gave a rather different justification for the claim that no proposition is expressed. Goldstein thought that the common source of the paradoxes are contradictory (or tautologous) specifying conditions. ${ }^{16}$ Sentences like (23), 'this is a fine red one', are what Goldstein called 'failed attempts' (FA). Any name we give to a token of a FA will also fail to designate a proposition. Let us refer to this as the cassatio approach (Goldstein, 2000, 57). ${ }^{17}$

Now, strategies like Goldstein's face objections. The main one is that it seems to provide resources for new strengthened paradoxes. If the objections stand, the proposal fails one of Horwich's pre-conditions regarding an acceptable approach to the liar: that no liar-like contradictions should follow.

For instance, Valor Abad and Martínez Fernández (2009) criticized Goldstein's cassatio approach. They summarize Goldstein's view as follows. S purports to name a typical strengthened liar, but is an unacceptable naming stipulation, whereas V is an acceptable name (Goldstein, 2000, 50).

$\left(\mathrm{S}_{d f}\right) \mathrm{S}_{=d f}$ the statement $\langle S$ is not true $\rangle$.

\footnotetext{
${ }^{16}$ I'll use "make a statement" and "express a proposition" interchangeably for present purposes.

${ }^{17}$ Notice however that the reason why (23) is a FA is that the context of its use does not provide the required salient object of the ostensive demonstration. The failure to make a statement is explained by the semantics for 'this'.
} 
$\left(\mathrm{V}_{d f}\right) \mathrm{V}_{=d f}$ the statement $\langle S$ is not true $\rangle$.

$\mathrm{V}$ is an acceptable stipulation because it is a statement about $\mathrm{S}$, and says that $\mathrm{S}$ is not true. S itself is a FA. (Goldstein, 2000, 59). Moreover, 'is not true' appears to mean different things in $\mathrm{V}$ and $\mathrm{S}$ - in $\mathrm{S}$ it means 'false' and in $\mathrm{V}$ it means 'not truth-apt' (Goldstein, 2000, 58), (Valor Abad and Martínez Fernández, 2009, 327-329).

Valor Abad and Martínez Fernández (2009) then introduce NS as a name for non-statements, i.e., sentence tokens that do not express propositions. They suggest that just as we can talk about a statement to discuss whether it is true or false, so we can talk about a non-statement to say that it is not true. Let $\mathrm{L}^{*}$ be the sentence ' $\mathrm{S}^{*}$ is not true' and let $\mathrm{S}_{d f}^{*}$ fix the meaning of ' $\mathrm{S}$ ':

$\left(\mathrm{S}_{d f}^{*}\right) \mathrm{S}_{=d f}^{*}$ the NS produced by the utterance of $\mathrm{L}^{*}$ in context $\mathrm{C}$.

Now, either $\mathrm{S}^{*}$ is a successful stipulation or it is not. If it is, the utterance of $\mathrm{L}^{*}$ in $\mathrm{C}$ produced a NS and ' $\mathrm{S}$ ' ' stands for it. But if in uttering ' $\mathrm{S}$ * is not true' in $\mathrm{C}$ an NS (the referent of ' $\mathrm{S}^{*}$ ') was assigned the property of not being true, then our utterance was a true statement after all, not an NS. Valor Abad and Martínez Fernández (2009) conclude, by reductio, that S* was an unsuccessful stipulation.

Is this a problem? I don't think it is, if we admit context-sensitivity in the picture. On the assumption that $\mathrm{S}_{d f}^{*}$ is a successful stipulation, ' $\mathrm{S}$ ' ' stands for a non-statement. But if ' $\mathrm{S}$ ', stands for a non-statement, it follows that we can't assign any truth-theoretic property to it, like that of being untrue. More specifically, if ' $\mathrm{S}$ ') stands for a non-statement then we can say that in the sentence $\mathrm{L}^{*}$ the predicate 'is not true' is ascribed to the referent of ' $\mathrm{S}$ ', , but not that the property of being untrue is ascribed or assigned to the referent of $\mathrm{S}$ - because ascribing or assigning properties to referents is what statements do, what constitutes a statement. However, we assumed, the use of the sentence in the context did not constitute a statement. Hence, we did not make a true statement after all. Therefore, the stipulation is successful and there is no problem, contra Valor Abad and Martínez Fernández (2009).

Although Goldstein $(2000,2001)$ offered a distinct explanation from the deflationist's of why no statement is made by a use of a liar sentence, and although Valor Abad and Martínez Fernández (2009)'s reply is specifically directed at Goldstein's cassatio approach, their rejoinder illustrates a type of response to the strategy of denying that paradoxical sentences express propositions. The 
type of strategy consists in using the justification of the restriction to generate a new strengthened paradox. As my response above suggests, a contextualist may have the resources to resist this strategy.

In the discussion above, we were talking of context $\mathrm{C}$. Let us rename it $\mathrm{C}_{1}$. In a different context, $\mathrm{C}_{2}$, we can say that $\mathrm{S}^{*}$ is not true. There is a given non-statement, $\mathrm{S}^{*}$, and it is not true, because non-statements have no truththeoretical properties, have no truth-conditions, etc. But we are not assigning the property of untruth to it. In $\mathrm{C}_{1}$, an utterance of a token of ' $\mathrm{S}$ ' ' is not true' is a non-statement, and lacks any truth-value. $\mathrm{In}_{2}$, an utterance of a token of ' $\mathrm{S}$ * is not true' makes a statement, and a true one, although what is stated is not that it is untrue, i.e., that it is false. $\mathrm{In}_{2}$, we say that a given non-statement does not have a certain property, not that it has a given property of untruth. What is said in $\mathrm{C}_{2}$ is not the same as the presumed statement made in $\mathrm{C}_{1}$, because no statement was made by uttering that sentence in $\mathrm{C}_{1}$.

In $\S 4.2$, I'll offer independent linguistic evidence in support of the different readings of 'not true' involved in this response: those that allow affixing 'un' to the truth predicate, and those that do not ascribe a truth-theoretical property to a sentence. It seeks to explain what is said in $\mathrm{C}_{2}$.

\subsection{Negation and Denial}

The reasoning used by, e.g., Valor Abad and Martínez Fernández (2009) could be taken as evidence for the semantic ambiguity of 'is not true', and as support for the semantic ambiguity of negation, as Simmons suggested in §3.2.

Nonetheless, that is not presumably the best, or only, option. ${ }^{18}$ Take sentence (23); is it true or not true? Well, neither: it doesn't make a statement. (23) is a meaningful sentence that does not state anything and is not truth-apt, because the demonstrative fails to successfully demonstrate. (23) does not have the property of being untrue - it is neither true nor untrue. It would be silly to introduce a new sentential connective to capture the sense of 'not true' that applies to (23), just as it would be silly to introduce a new sentential connective to capture the sense in which my desk is not true. We are not saying that (23) is untrue, after all.

There are uses of negation + predicate that admit of a transformation with affixal negation, ${ }^{19}$ as in examples like:

\footnotetext{
${ }^{18} \mathrm{I}$ argued against using paradoxes as a reason to stipulate, or introduce, the semantic ambiguity of negation in [Author2008; Author2010].

${ }^{19}$ For a discussion of affixal negation, see for instance Horn (2001) (Horn, 2001, §5.1).
} 
- true/untrue

- friendly/unfriendly

- just/unjust

- happy/unhappy

- fertile/infertile

- competent/incompetent

As the examples show, both the positive and the negative terms designate properties. Furthermore, prima facie there are no things that have the two properties at the same time. But there are many things that have neither: the Moon is neither happy nor unhappy; this banana is neither competent nor incompetent, Obama is neither true nor untrue, etc.

As the examples show, not all uses of negation + predicate are equivalent to affixal negation + predicate. In fact, as the '(23) is neither true nor untrue' example testifies, we should resist interpreting all uses of negation + predicate as designating a truth-theoretic property.

Not all uses of negation + predicate are equivalent to affixal negation + predicate. In some cases, negation takes wide scope over sentences with other operators. In other uses of negation, negation is interpretable as metalinguistic negation. Metalinguistic negation is a pragmatic mechanism that offers two benefits in the context of debating the liar paradoxes: (a) metalinguistic negation exists and is independently explainable, and (b) it explains felicitous uses of utterances like "Obama is not true" that don't commit us to ascribing to Obama the property of being untrue.

Horn (2001) calls metalinguistic negation some of these felicitous uses of negation, which he suggests can be interpreted as 'I object to U'. Through metalinguistic negation, a speaker objects to an aspect of previous utterance of a sentence. The domain of application of this mechanism is rather broad. Standard examples include presupposition-cancelation, such as:

I don't regret going to the dinner - the dinner was cancelled in the last minute.

Cases of presupposition-cancelation have a distinct marked reading, which can be followed by a correction clause usually interpreted as the negation of the presupposition. Something similar goes on with (32). 
An utterance of Strawson's example (23) 'this is a fine red one' presupposes that the speaker successfully demonstrated something in context. But that presupposition can be canceled, as (32) does below. In (32), 'this is not red' is not to be understood descriptively, as saying how things are in the world. It corrects a mistake in a (potential) utterance of the corresponding positive sentence.

(32) [Two children are playing. Child A has to close her eyes and guess the color of the objects child B points at. B says:] Ah! This is not red! I'm not pointing at anything!

In examples like (32), negation serves to reject the presupposition that there was a salient object ostensibly demonstrated in context.

Metalinguistic negation's range of application goes beyond presuppositioncancelation. It can focus on diverse objectionable features of sentence-use, from conversational implicatures to pronunciation.

The Queen of England is not happy; she's ecstatic.

She didn't flaunt Grice's maxims, she flouted them.

Sir Ralph won't buy tom[eiDouz]; he'll buy tom[a:touz]

Philosophers have appealed to the mechanism of metalinguistic negation to handle various sorts of philosophical problems. In metaethics, for instance, Stephen Barker (2000) appeals to different ways of denying an utterance of a sentence as a way of explaining moral disputes. He called the two forms of negation 'explicature-based' and 'implicature-based' negation. Explicature based is truth-conditional negation, the denial of the literal content asserted. Implicature-based is the denial of other implicated content that is not literally asserted.

My favored approach to metalinguistic negation, or denial, is Robyn Carston's (Carston $(1996,1998))$. On her view, natural language negation is neither semantically nor pragmatically ambiguous. Rather, some of the material in its scope can sometimes be used metarepresentationally or echoically. Metarepresentational uses represent another representation for some purpose. They don't reassert the represented content.

There are also examples of metarepresentational echoic uses of expressions that do not involve negation. In the following dialogue, A overhears the conver- 
sation between $\mathrm{B}$ and $\mathrm{C}$, where they use a pejorative to refer to A:

a. (B says to $\mathrm{C}:$ ) $\mathrm{A}$ is such a bitch.

b. (A, who overheard them:) The bitch can hear you!

Here, A does not self-ascribe the pejorative 'bitch'. Her use of the word is echoic of B's use, and serves to communicate that B's utterance is inappropriate.

I am assuming, with Beall (2001), Asay (2015), and Goldstein (2000, 2001), that the minimalist has ways to justify the claim that the liar-like sentences express no proposition. I don't want to commit to any single justification of this claim. My inclination is to adopt a contextualist justification that applies to 'true' semantic constraints on its appropriate use in context, in a similar way that successful uses of 'this' or 'tall' demand the satisfaction of presuppositional constraints on their contexts.

I argued that the minimalist can justifiably deny that paradoxes like the liar express propositions. I have provided semantic and pragmatic evidence of a variety of uses of negation. This gives the minimalist the resources to explain how we can correctly reject the notion that the truth-predicate applies to liar sentences without falling back into paradox. The evidence can be summarized in (i)-(iii):

(i) Not all uses of not + predicate permit affixing a negative particle un or in to the predicate;

(ii) Typically, a predicate with affixal negation expresses a property;

(iii) Some uses of negation are metarepresentational and echoic and don't focus on truth-conditional content.

Various authors have proposed a very different way to discriminate between uses of negation. The more standard alternative is to argue for the difference between asserting a negation and making a denial. Authors like Parsons (1984) argued that we should not confuse the rejection of a sentence with the assertion of its negation (Parsons, 1984, 150). He claimed that there is a difference between two kinds of speech-acts: rejecting $\langle p\rangle$ and asserting $\langle$ not- $p\rangle$, and that this difference allows us to reject paradoxical sentences without producing strengthened paradoxes. As evidence, Parsons gives examples of presupposition-cancelation that fall under the label metalinguistic negation. In addition, Tappenden (1999) offered a broader application of the distinction between denying and asserting a negation as a way to reject various problematic cases, including the liar. 
Now, insofar as the supporting linguistic evidence for a speech-act of denial goes, there is not much to ground its existence. As Carston (1998) and Geurts (1998) argue, there are convincing reasons to think that metalinguistic negation is just ordinary negation used in special contexts to pragmatically communicate the negation of some non-literal content. ${ }^{20}$

Let us take stock. One option for Horwich is to treat 'true' as contextsensitive. As I've suggested, this is compatible with treating different uses of a sentence such as '(1) is not true' as making different contributions depending on the context of use. In context $\mathrm{C}_{1}$, ' (1) is not true' may express no proposition. The use of the sentence at $\mathrm{C}_{1}$ does not specify its own conditions for being true. In context $\mathrm{C}_{2}$, however, a use of '(1) is not true' metarepresents the sentence as it occurred at $\mathrm{C}_{1}$, but does not assert '(1) is not true'. The fact that the metarepresentational use of the sentence at $\mathrm{C}_{2}$ communicates something true does not allow us to infer that (1) is untrue.

This alternative can use Beall's justification for the failure of the liar sentence to express a proposition, and be complemented by the idea that uses of certain sentences are echoically or metarepresentationally denied. Prima facie, the minimalist contextualist approach does not conflict with the central tenets of minimalism: that is, that truth is a denominalizing function, and it is entirely captured in the fact that each proposition specifies its own condition for being true.

\subsection{Problems ahead?}

Does the present minimalist contextualist proposal fare better than Horwich's epistemicism in the face of objections?

The charge of loss of expressibility and explanatory power in a deflationist truth-theory that Beall and Armour-Garb (2003) pointed to can be summarized thus: there is a loss in expressibility because deflationism admits that there are propositions that may be true but cannot instantiate the truth-schema. It entails a loss in explanatory power because minimalism purports to capture all facts about truth through instances of the truth-schema, but it admits the existence of (possibly) true propositions that are not legitimate instances of (E), and hence of truths that fall outside the remit of the theory. There are also apparently paradoxical sentences related to the liar whose paradoxicality cannot

\footnotetext{
${ }^{20}$ Ripley (2011) points to other problems that arise for the idea that negation and denial are separate independent phenomena.
} 
be explained by the theory. If, as Asay (2015) argues, the liar and a range of related biconditionals express propositions that are either true or false, there is a very large number of truth-valued propositions whose truth (or falsity) is not explained. That loss of explanatory power undermines the theory that purports to capture all there is to say about truth.

If, on the contrary, minimalism admits that the truth-predicate is contextdependent, denies that paradoxical sentences express propositions, and explains some uses of 'not true' as echoic or metarepresentational, it does not lose expressibility or explanatory power. Sentence (11), 'Everything that Tarski said on 27 March 1934 is true', should allow us to make the appropriate inferences predicted by the theory. Minimalism is a theory about a property of propositions. Hence, the quantifier in (11) ranges over propositions, "the things that are believed, stated, supposed, etc." (Horwich, 1990, 16). If the only thing Tarski uttered on 27 March 1934 was sentence (1), and (1) does not express a proposition, then Tarski stated nothing on 27 March 1934.

Moreover, the odd "logic of paradox" that Asay (2015) shows to be a problem for minimalism is no longer a problem. He showed that 'false'/"not true' behave with paradoxical sentences like 'true' does with ordinary sentences, i.e., as a denominalizer. This was a problem because it would either entail a contradiction, make minimalism trivial, or undermine minimalism. If paradoxical sentences express no propositions, the problem does not arise.

'True' expresses denominalizing properties captured in correct instances of (E). Can all occurrences of the predicate 'true' in a sentence be eliminated? No, not all uses of apparently meaningful uses of the word 'true' are eliminable. On the hypothesis of a contextualist minimalist approach, there are ineliminable uses of 'true' like that in (1). There are also correct ineliminable uses, but (at least some, as shown) can be treated as metarepresentational uses of 'not true'. Metapresentational uses of expressions in language play an important pragmatic role in discourse. The hypothesis of a metarepresentational use of 'not true' is compatible with the minimalist contextualist approach.

This is not to say that the contextualist minimalist proposal won't face new challenges. As a critic asked: This might seem to be a radical proposal and would need defense, since some ungrounded sentences, like the truth-teller, intuitively are straightforwardly true. This is important. One' reasonably worry that paradox and inconsistency aside there are ungrounded sentences with truthvalues such that Horwich's account is unable to account for how they receive their truth-values. 
However, I very much doubt that there are any pre-theoretic reliable intuitions that should guide our theorizing here. Earlier I quoted Simmons when he said that "The Truth-Teller (J) will be reflectively evaluated as false" (Simmons, 1999, 471). Kripke (1975) treated the truth-teller as ungrounded (Kripke, 1975, 694). Although what Kripke means by 'ungrounded' is a property of sentences, and is specific to his theory, what matters for present purposes is that neither he nor Simmons share the intuition that the truth-teller sentence is true. There is no prima facie reason to take the latter intuition more seriously than the alternatives. ${ }^{21}$ To say that there are ungrounded sentences that have truth-values, on the contextualist Lewisian modification of minimalism I proposed here, would be to admit that there are uses of sentences whose contexts of use don't provide the required semantic values. As a result, utterances of those sentences don't supervene on anything that exists or could have existed, but are nonetheless truth-valued. I find the idea incredible. ${ }^{22}$

A further worry is that we may be relying dangerously on the idea that truths and falsehoods ultimately depend on what makes them true/false, and that may be a concession to truthmaker theory, or to a correspondence theory of truth. The final question leaves a potential problem for Horwich. In the final discussion of his paper, Asay (2015) committed only to a minimal claim about truthmaking: that what is true supervenes on what exists, and on the properties existing things have. Horwich (2008) argues that truthmaker theory is not a theory of truth, and Lewis (2001) agrees. Thus, the minimal supervenience claim in itself need not be a problem.

The minimal supervenience claim is that what is true supervenes on what exists, and on the properties existing things have. We are assuming, with Horwich, that what is primarily true are propositions, and that sentences (as used in context) are derivatively true. Hence, a sentence as used in a context supervenes, via the proposition it expresses, on what exists; if there's no supervenience relation on reality, nothing could have existed that would have made a difference, and no proposition is expressed.

\footnotetext{
${ }^{21}$ In fact, in the first footnote of his paper, Kripke says "I have chosen to take sentences as the primary truth vehicles not because I think that the objection that truth is primarily a property of propositions (or "statements") is irrelevant to serious work on truth or to the semantic paradoxes... Occasionally we may speak as if every utterance of a sentence in the language makes a statement, although below we suggest that a sentence may fail to make a statement if it is paradoxical or ungrounded"'(Kripke, 1975, fn 1).

${ }^{22}$ It is worth noting that Sorensen (2001) denies Lewis's insight that truths must supervene on what exists, and defends the claim that there are truths with no truthmakers, i.e., that there are truthmaker gaps. I briefly discuss this below at the end.
} 
Now, the liar sentence (and the truth-teller sentence) do not supervene on anything that exists, or on any properties of existing things. Nothing that could have existed would have made a difference. There is a striking difference between these types of sentences and sentences that are indeterminate due to vagueness, like "Sally is tall": things could have been such that the sentence, saying what it does, could have been determinately true. The contextualist proposal says not just that what is true supervenes on what exists, but also that propositions supervene on what exists, on what might have existed, and their properties. Saying that what propositions there are supervene on what exists, and their properties, is not the same as endorsing a correspondence theory of truth. But it requires a more substantive answer about the nature of propositions, perhaps that a proposition is a class of possible worlds. This response may require an account of possible worlds that, if Horwich's concerns about conceptual priority are relevant, does not rely on truth.

Before finishing this paper, it is worth contrasting the suggestion I advance here with a defense of an epistemicist view that is prima facie close to Horwich's. The suggestion I advance here is that minimalism about truth can accept contextualism about the truth-predicate and Lewis's difference-maker insight, while rejecting the idea that paradoxical sentences express propositions. Yet, Sorensen (2001) defends a form of epistemicism that is similar to Horwich's, and which bravely rejects Lewis's insight. Sorensen suggests that deflationism naturally fits with epistemicism, and argues that epistemicism about the liar is as plausible as epistemicism about vagueness (Sorensen, 2001, ch. 11). He takes the opposite direction from the one I argue for in this paper, and argues instead for the existence of truthmaker gaps, that there are truths that do not supervene on reality in any way.

The Lewisian difference-maker insight, coupled with Horwich's account of ungroundedness (something is ungrounded if it is not entailed by any nontruth-theoretic facts), provides minimalism with the resources to defend the no-proposition view about paradoxical sentences. To recall, Lewis's insight is this:

I borrow a slogan from John Bigelow: 'Truth is supervenient on being'... I want to construe 'being' broadly: it covers not only whether things are, but also how they are. Then the slogan means that no two possibilities can differ about what's true unless they also differ in what things there are, or in how they are. (Lewis, 1999, 2016) 
However, Sorensen questions Lewis's difference-maker principle. ${ }^{23}$ Sorensen combines deflationism and epistemicism to justify the existence of truthmaker gaps. First, Sorensen suggests, 'true' does little more than remove quotation marks and serve as a sentence variable (Sorensen, 2001, 165). Second, he claims that "talk of 'facts' is similarly thin and linguistic" because facts and truths are just two sides of the same slim coin (Sorensen, 2001, 165). In the third place, and after Herzberger (1970), the laws of logic are counterexamples to the idea that the truth of a sentence needs to be grounded within the real world. Laws of logic are (necessarily) true, but are not grounded within the real world. Hence, we cannot ban ungroundedness. Sorensen claims that the ban on ungroundedness is as bad as the ban on self-reference. Banning ungroundedness would entail a ban of the laws of logic "on their naïve construal (as statements about all statements including themselves) along with the general principles of semantic theory including the grounding condition itself" (Sorensen, 2001, 167-168). In the fourth place, Sorensen believes that there are independent reasons in favor of epistemicism, the idea that there are truths that cannot be known. He claims that these truths are epistemic islands: sentences that may be true, even if there is no "access to their truth via a truthmaker" (Sorensen, 2001, 165). In other words, there are truths that do not have truthmakers - i.e., there are truthmaker gaps.

Epistemicism is one of the main theories about vagueness, and the question is whether it can plausibly be extended to semantic paradoxes. Sorensen's view is that it can, and illustrates it by arguing that the no-no paradox is an epistemic island. A no-no paradox is a variation of the liar paradox, for instance one where on one side of a card the sentence "the sentence on the other side of this card is not true" and on the reverse of the same card we can read another token of this sentence. Symmetry considerations, and the absence of any contextual difference, militate against differentiating between the truth value of the sentences in the no-no paradox. Now, Sorensen claims that the no-no paradox is a counterexample to the difference-maker principle, that truths supervene on what exists.

Since our central question here is whether semantic paradoxes are (a) truthvalued sentences without truthmakers, or (b) truth-valueless because they express no propositions, we cannot rely on the no-no paradox as a putative counterexample to the difference-maker principle.

${ }^{23}$ Lewis further develops the principle in Lewis (2001). 
Let us assume classical logic, with Horwich and Sorensen, and assume deflationism (in some form or other, for sentences or propositions). We have then two options. We can follow Sorensen's suggestion to drop the differencemaker requirement, and treat truth just as a disquotational device without the difference-maker requirement. A consequence of assuming deflationism within classical logic, dropping supervenience is, as Asay shows (§3.2.), that 'true' ends up denoting the same property for non-paradoxical sentences as 'untrue'/'false' denotes for paradoxical sentences. And a consequence of this is that (a) either there is nothing else to say about truth, and minimalism is either contradictory or trivial, or (b) there is more to say about truth, but minimalism is wrong, which contradicts the deflationist assumption we started with.

Nonetheless, we have a second option. If we're inclined to agree, as Horwich is, with the minimum difference-maker insight, and have independent doubts about assigning truth-values to paradoxical sentences, then we have no good reason to regard the no-no paradox by itself as a counterexample to the differencemaker principle. Now, the main concern with the difference-maker principle is about the status of logical laws, a concern that is inspired by Herzberger (1970). Yet, the appeal to the necessary truth of laws of logic as a reason not to ban ungroundedness, and to drop the difference-maker principle, is disputable. There are competing theories about the nature of the laws of logic, and the source of their normative force. Maybe these theories are also disputable, but they do offer grounds for the laws of logic - something on which logic supervenes: either conventions (Carnap (1937)), the logical structure of the world (Wittgenstein (1922)), or our own minds or cognitive structure (for instance, Craig (1985) on how modality, hence necessity, is thinker-dependent. For discussion, see also Peacocke (1999), pp. 177 ff.). Hence, arguably, even laws of logic are grounded on something.

Sorensen's suggestion is a curious form of epistemicism. Epistemicism is a view that is intelligible insofar as the claim that there are facts that cannot be known is intelligible and defensible. But truthmaker gap epistemicism, as Sorensen proposes, entails that there are the thinnest kinds of truths/falsehoods, but that they don't supervene on reality in any way (except on themselves, presumably). There are no facts to be known, because there are no facts. There is nothing that we are ignorant of concerning those truths. 'True' is really just an operator with a specific functional role. This is problematic (see Asay's objection). A further problem with Sorensen's truthmaker gap epistemicism is that it entails that there are two kinds of facts: thin 'linguistic' facts, and robust 
difference-maker facts.

Truthmaker gap epistemicist offers an apparently interesting and exciting theory, one in which there are truths that cannot be known and where our commitment to classical logic is unshaken. However, and ultimately, the unknowable truths epistemicism offers us are emaciated thin linguistic "facts". On Horwich's minimalism, truth is a property of propositions, and they are not just linguistic entities. In this paper, I have argued that Horwich should reject the idea that semantic paradoxes like the liar express propositions, rather than just saying that paradoxes cannot adequately instantiate the truth-schema (E). Merely restricting acceptable instances of the schema raises a series of problems, as the earlier sections of this paper argued: the solution is ad hoc, it faces possible loss of expressibility, and is ultimately unstable. Instead, I suggested, minimalism is compatible with treating the truth predicate as context-dependent, and with treating negation in some contexts as metalinguistic denial. Moreover, Horwich (2008) is already disposed to accept the difference-maker principle, since it is not a principle about truth, but a metaphysical point about what exists. He

only needs to take the further step of accounting for what propositions there are by means of the difference their existence makes.

\section{References}

Asay, J. (2015). Epistemicism and the liar. Synthese 192(3), 679-699.

Ayer, A. J. (1935). The criterion of truth. Analysis 3(1/2), 28-31.

Barker, S. J. (2000). Is value content a component of conventional implicature? Analysis 60(267), 268-279.

Beall, JC. (2001). A neglected deflationist approach to the liar. Analysis $61(270), 126-129$.

Beall, JC. and B. Armour-Garb (2003). Should deflationists be dialetheists? Noûs 37(2), 303-324.

Beall, JC. and B. Armour-Garb (2005). Minimalism, epistemicism, and paradox. In JC. Beall and B. Armour-Garb (Eds.), Deflationism and Paradox, pp. 8596. Oxford: Oxford University Press.

Carnap, R. (1937). The Logical Syntax of Language. London, K. Paul, Trench, Trubner \& Co., Ltd.

Carston, R. (1996). Metalinguistic negation and echoic use. Journal of Pragmatics 25, 309-330. 
Carston, R. (1998). Negation, 'presupposition' and the semantics/ pragmatics distinction. Journal of Linguistics 34, 309-350.

Craig, E. (1985). Arithmetic and fact. In I. Hacking (Ed.), Exercises in Analysis. Cambridge University Press.

Field, H. (1986). The deflationary conception of truth. In G. MacDonald and C. Wright (Eds.), Fact, Science and Morality, pp. 55-117. Blackwell.

Field, H. (1994). Deflationist views of meaning and content. Mind 103(411), 249-285.

Field, H. (2001). Saving the truth schema from paradox. Journal of Philosophical Logic 31(1), 1-27.

Field, H. H. (2008). Saving Truth From Paradox. Oxford University Press.

Geurts, B. (1998). The mechanisms of denial. Language 74(2), 274-307.

Goldstein, L. (2000). A unified solution to some paradoxes. Proceedings of the Aristotelian Society 100(1), 53-74.

Goldstein, L. (2001). Truth-bearers and the liar - a reply to Alan Weir. Analysis $61(2), 115-126$.

Herzberger, H. G. (1970). Paradoxes of grounding in semantics. Journal of Philosophy 67(6), 145-167.

Horn, L. (2001). A Natural History of Negation (Reissue ed.). CSLI.

Horwich, P. (1998). Meaning. Oxford: Oxford University Press.

Horwich, P. (1998/1990). Truth (2nd ed.). Oxford: Clarendon Press.

Horwich, P. (2005). A minimalist critique of Tarski on truth. In JC. Beall and B. Armour-Garb (Eds.), Deflationism and Paradox, pp. 75-84. Oxford: Oxford University Press.

Horwich, P. (2008). Being and truth. Midwest Studies in Philosophy 32(1), $258-273$.

Horwich, P. (2010). Truth-Meaning-Reality. Oxford University Press.

Kaplan, D. (1989). Demonstratives. In J. Almog, J. Perry, H. K. Wettstein, and D. Kaplan (Eds.), Themes From Kaplan. Oxford University Press, USA.

Kennedy, C. and L. McNally (2005). Scale structure and the semantic typology of gradable predicates. Language 81(2), 1-37.

Kripke, S. A. (1975). Outline of a theory of truth. Journal of Philosophy 72(19), 690-716. 
Kürbis, N. (2015). What is wrong with classical negation? Grazer Philosophische Studien 92, 51-86.

Lewis, D. (1980). Index, context, and content. In Philosophy and Grammar, pp. 79-100. Reidel.

Lewis, D. (1999). Armstrong on combinatorial possibility. In Papers in Metaphysics and Epistemology: Volume 2, pp. 196-214. Cambridge University Press.

Lewis, D. (2001). Truthmaking and difference-making. Noûs 35(4), 602-615.

Lewis, D. K. (1998). Papers in Philosophical Logic. Cambridge University Press.

Parsons, T. (1984). Assertion, denial, and the liar paradox. Journal of Philosophical Logic 13(2), 137-152.

Peacocke, C. (1999). Being Known. Oxford University Press.

Quine, W. V. (1970/1986). Philosophy of Logic. Harvard University Press.

Ramsey, F. P. (1927). Facts and propositions. Proceedings of the Aristotelian Society 7(1), 153-170.

Ripley, D. (2011). Negation, denial, and rejection. Philosophy Compass 6(9), 622-629.

Simmons, K. (1999). Deflationary truth and the liar. Journal of Philosophical Logic 28(5), 455-488.

Soames, S. (1999). Understanding Truth. Oxford: Oxford University Press.

Sorensen, R. (1988). Blindspots. Oxford University Press.

Sorensen, R. (2001). Vagueness and Contradiction. Oxford University Press.

Stalnaker, R. (1978). Assertion. Syntax and Semantics (New York Academic Press) 9, 315-332.

Stalnaker, R. (2002). Common ground. Linguistics and Philosophy 25(5-6), $701-721$.

Stalnaker, R. (2014). Context. OUP Oxford.

Strawson, P. F. (1950). Truth. Aristotelian Society Supplementary Volume 24, $111-172$.

Tappenden, J. (1999). Negation, denial, and language change in philosophical logic. In D. Gabbay and H. Wansing (Eds.), What is Negation?, pp. 261-298. Springer. 
Tarski, A. (1936). The concept of truth in formalized languages. In A. Tarski (Ed.), Logic, Semantics, Metamathematics, pp. 152-278. Oxford University Press.

Valor Abad, J. and J. Martínez Fernández (2009). A failed "cassatio": Goldstein on the liar. Proceedings of the Aristotelian Society 109, 327-332.

Williamson, T. (1994). Vagueness. London: Routledge.

Wittgenstein, L. (1994/1922). Tractatus Logico-Philosophicus (Trans. Pears and McGuinness). Routledge. 